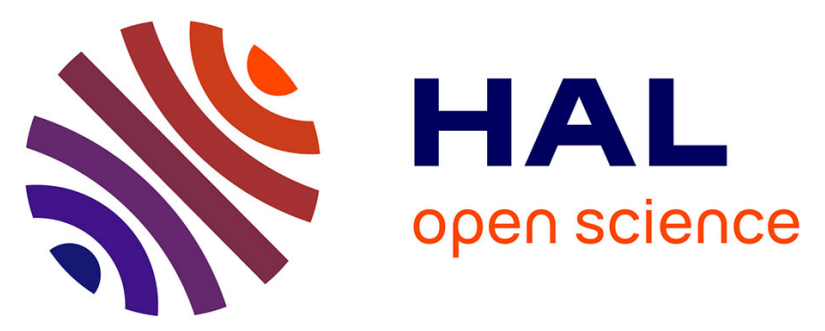

\title{
Simulation Analysis for Demonstrating the Economic Competitiveness of Busan Port in the Northeast Asia
}

Ilkyeong Moon, Qian-Ru Shen, Xuehao Feng

\section{To cite this version:}

Ilkyeong Moon, Qian-Ru Shen, Xuehao Feng. Simulation Analysis for Demonstrating the Economic Competitiveness of Busan Port in the Northeast Asia. IFIP International Conference on Advances in Production Management Systems (APMS), Aug 2018, Seoul, South Korea. pp.406-414, 10.1007/9783-319-99704-9_50 . hal-02164875

\section{HAL Id: hal-02164875 \\ https://hal.inria.fr/hal-02164875}

Submitted on 25 Jun 2019

HAL is a multi-disciplinary open access archive for the deposit and dissemination of scientific research documents, whether they are published or not. The documents may come from teaching and research institutions in France or abroad, or from public or private research centers.
L'archive ouverte pluridisciplinaire HAL, est destinée au dépôt et à la diffusion de documents scientifiques de niveau recherche, publiés ou non, émanant des établissements d'enseignement et de recherche français ou étrangers, des laboratoires publics ou privés. 


\title{
Simulation Analysis for Demonstrating the Economic Competitiveness of Busan Port in the Northeast Asia
}

\author{
Ilkyeong Moon ${ }^{1 *}$, Qian-Ru Shen ${ }^{2}$, Xuehao Feng ${ }^{3}$ \\ ${ }^{1}$ Department of Industrial Engineering, Seoul National University, Seoul, Korea \\ ${ }^{2}$ Beijing CaoZiTou Aesthetic Co.Ltd, Beijing, China \\ ${ }^{3}$ Ocean College, Zhejiang University, Zhoushan, China
}

\begin{abstract}
Container traffic between Busan and Japan is continuously blooming as the global economy grows impressively. It is interesting to see that Busan in Korea has great potential to be considered as a transit port for container export/import in Japan instead of Japanese domestic transit ports, due to the special geographic location and economical container handling cost. This paper attempts to demonstrate the economic competitiveness of Busan port for container transshipment. It describes models for analyzing the container transportation time and cost by transshipment mode, specifically, transferring via the ports of Japan vs. via Busan. A simulation programming method is developed to build the models. A case study which considers twenty Japanese regional cities has been presented. According to the comparison of simulation results and sensitivity analysis, the paper concludes with a discussion and suggestions for the container transportation transshipment network design of Japan.
\end{abstract}

Keywords: simulation, container, transshipment, network design

\section{Introduction}

With the continuous growth of the international trade cooperation of the world, containerization becomes progressively popular for commodity transportation. Japan, as one of the most important trade nations in Asia, has a very large import and export trade volume. Currently, the five major ports (Tokyo, Nagoya, Osaka, Yokohama, and Kobe) are assuming the role of handling most of the container traffic in Japan. Containers are firstly transferred by trucking from regional cities to major ports. Then the mode shifts from trucking to shipping, and the containers are transported by Ultra Large Containerships (ULCS) from the major ports to destinations. However, for some routes of container transportation in Japan, the handling cost and inland transportation cost in Japan is relatively high, and the recent financial crisis and ensuing worldwide economic recession have meant that enterprises are trimming their transportation budget. A more economic, competitive way of container transportation may be considered.

The purpose of our research is to find the best container transportation routes for regional cities in Japan and establish the economic competitiveness of Busan port and the benefits that can be obtained when Busan is used for transshipment. The study focuses on the time and cost comparison of two types of intermodal container transportation. Few previous investigations of container transportation simulation models have been found by us, besides that of Cortes et al. [4], who presented a simulation model of freight traffic in the Seville inland port. For most of the other existing research, simulation 
has been used to visualize the process inside container ports, e.g. container terminal planning (Kim and Kim [5]), layout planning (Bruzzone and Singnorile [6]), planning of maritime traffic (Kose et al. [7], Hayuth et al. [8]).

\section{The Container Transportation Model}

\subsection{Candidate Ports and Cities}

Twenty regional cities and twenty regional ports having a one-to-one relationship are considered in this study, which means that the containers of each regional city will be transported to the nearest regional port. Five domestic ports of Japan and Busan are the transit ports; the main variations in this simulation comparison arise from the transit process. In addition, one destination ports are considered, all of which are in North America. Detailed information on the cities and ports is displayed in Table 1. As there are two optional regional ports for Yamaguchi city to transit, we marked them as Yamaguchi_1 and Yamaguchi_2 to distinguish.

Table 1. Candidate ports and cities

\begin{tabular}{cccc}
\hline Regional City & Regional Port & Transit Port & Destination \\
\hline Sapporo & Tomakomai & & \\
Aomori & Hachinohe & Busan & \\
Akita & Akita & & \\
Sendai & Sendai & & \\
Niigata & Niigata & Tokyo & \\
Toyama & Toyama & & \\
Kanazawa & Kanazawa & & \\
Shizuoka & Shimizu & Yokohama & \\
Tsu & Yokkaichi & & \\
Okayama & Mizushima & & \\
Hiroshima & Hiroshima & Nagoya & \\
Yamaguchi_1 & Tokuyama & & \\
Yamaguchi_2 & Shimonoseki & & \\
Matsuyama & Matsuyama & Kobe & \\
Kitakyushu & Kitakyushu & & \\
Hukuoka & Hakata & & \\
Saga & Imari & & \\
Oita & Oita & \multirow{2}{*}{ Osaka } & \\
Kagoshima & Shibushi & & \\
Naha & Naha & & \\
\hline
\end{tabular}

\subsection{Model Logic}

The simulation model compares the total cost and time between two transshipment modes: via Busan and via Japan.

\section{Mode via Busan}

1) Containers are transported by truck from a regional city to a regional port in Japan. 
2) A feeder ship is used for transporting containers from the regional port in Japan to Busan.

3) Containers are transferred to ULCS at Busan port and transported to North America.

\section{Mode via Japan}

1) Containers are transported by inland transportation (truck) from a regional Japanese city to a major port in Japan.

2) As with the case of Busan, maritime transportation by ULCS transfers the containers to North America.

\subsection{Assumptions}

1) We only consider the transportation of $20 \mathrm{ft}$ container in this simulation model, as the specification of container truck in Japan is 20ft [9].

2) Only one TEU container is considered for transportation from regional cities to North America, which means after one TEU container has been transferred to the destination, the next container arrives. There is no container aggregation in this model.

3) Containers may wait in the port due to the mismatch between the arrival time and departure schedule. During the waiting time, the loading and unloading service for the container can be completed, that is, the service time of container loading and unloading is not considered.

\section{Simulation Approach}

\subsection{Data Analysis}

Processed Data. Usually, input data collection represented a significant portion that $30 \%$ of total project effort and time [10]. Thus, firstly we collected raw data from Japanese publications, and processed them before using them as the simulation input data [11-13]. For a shipping route that may be served by more than one shipping company, we selected the shortest transportation time. In case there was a direct route, obviously, the direct route was chosen ahead of the transshipment route. If there was no direct route, the transshipment time was selected. We also collected the shipping time schedule of each candidate port. The phenomenon of scheduling mismatches can be accurately simulated by ARENA. Table 2 show the information on shipping lines from the transit ports to North America. We chose Long Beach to represent the ports of North America. Table 3 displays the information on the times of shipping lines from regional Japanese ports to Busan port.

Table 2. Information on the time from Busan and major Japanese ports to Long Beach (Unit: days)

\begin{tabular}{|c|c|c|c|c|c|c|}
\hline \multirow{2}{*}{ Transit Port } & \multirow{2}{*}{$\begin{array}{c}\text { Average Waiting Time } \\
\text { (days) }\end{array}$} & \multicolumn{3}{|c|}{ Transportation Time(days) } & \multirow{2}{*}{$\begin{array}{l}\text { Frequency } \\
\text { (time/week) }\end{array}$} & \multirow{2}{*}{ Pattern } \\
\hline & & Min & Mean & Max & & \\
\hline Busan & 1.214 & 10.0 & 10.3 & 11.0 & 3 & Direct \\
\hline Tokyo & 2.071 & 7.2 & 9.0 & 10.8 & 2 & Direct \\
\hline Osaka & 3.500 & 8.0 & 10.0 & 12.0 & 1 & Transshipment \\
\hline Yokohama & 3.500 & 9 & 9.5 & 10 & 1 & Transshipment \\
\hline Kobe & 3.500 & 8.8 & 11.0 & 13.2 & 1 & Transshipment \\
\hline Nagoya & 3.500 & 8.0 & 10.0 & 12.0 & 1 & Transshipment \\
\hline
\end{tabular}


Table 3. Information on the time from regional Japanese ports to Busan (Unit: days)

\begin{tabular}{|c|c|c|c|c|c|c|}
\hline \multirow{2}{*}{ Regional Port } & \multirow{2}{*}{$\begin{array}{c}\text { Average Waiting Time } \\
\text { (days) }\end{array}$} & \multicolumn{3}{|c|}{ Transportation Time(days) } & \multirow{2}{*}{$\begin{array}{c}\text { Frequency } \\
\text { (time/ } \\
\text { week) }\end{array}$} & \multirow[b]{2}{*}{ Pattern } \\
\hline & & Min & Mean & $\operatorname{Max}$ & & \\
\hline Hakata & 0.929 & 0.5 & 0.8 & 1.0 & 9 & Direct \\
\hline Tomakomai & 3.500 & 2.4 & 3.0 & 3.6 & 1 & Direct \\
\hline Niigata & 0.786 & 3.0 & 4.0 & 5.0 & 6 & Transshipment \\
\hline Hiroshima & 2.643 & 0.8 & 1.0 & 1.2 & 2 & Direct \\
\hline Naha & 3.500 & 2.4 & 3.0 & 3.6 & 1 & Direct \\
\hline Shimizu & 1.071 & 3.0 & 4.0 & 5.0 & 7 & Transshipment \\
\hline Akita & 2.071 & 1.6 & 2.0 & 2.4 & 3 & Direct \\
\hline Shibushi & 3.500 & 0.8 & 1.0 & 1.2 & 1 & Direct \\
\hline Sendai & 1.500 & 3.0 & 3.3 & 4.0 & 3 & Transshipment \\
\hline Shimonoseki & 0.643 & 1.0 & 1.3 & 2.0 & 6 & Transshipment \\
\hline Kitakyushu & 0.643 & 0.5 & 0.9 & 1.0 & 13 & Direct \\
\hline Matsuyama & 3.500 & 0.8 & 1.0 & 1.2 & 1 & Direct \\
\hline Oita & 3.500 & 0.8 & 1.0 & 1.2 & 1 & Direct \\
\hline Yokkaichi & 3.500 & 2.4 & 3.0 & 3.6 & 1 & Direct \\
\hline Mizushima & 2.643 & 0.8 & 1.0 & 1.2 & 2 & Direct \\
\hline Hachinohe & 2.071 & 2.4 & 3.0 & 3.6 & 2 & Transshipment \\
\hline Toyama & 1.786 & 1.0 & 1.5 & 2.0 & 2 & Direct \\
\hline Tokuyama & 2.643 & 0.8 & 1.0 & 1.2 & 2 & Direct \\
\hline Kanazawa & 1.214 & 2.0 & 2.8 & 5.0 & 4 & Transshipment \\
\hline Imari & 2.643 & 2.0 & 2.5 & 3.0 & 2 & Transshipment \\
\hline
\end{tabular}

We assume that the transportation speed is $50 \mathrm{~km} / \mathrm{hour}$; thus, the transportation time can be obtained by dividing the distance by speed. The handling cost of each port is presented in Table 4, and we assume that the handling costs of Japanese transit ports are all the same.

Table 4. Handling cost of each port (Unit: Yen/TEU)

\begin{tabular}{cccc}
\hline Port & Handling Cost & Port & Handling Cost \\
\hline Hakata & 14,580 & Matsuyama & 10,605 \\
Tomakomai & 10,605 & Oita & 10,605 \\
Niigata & 14,580 & Yokkaichi & 17,100 \\
Hiroshima & 14,580 & Mizushima & 20,000 \\
Naha & 10,605 & Hachinohe & 10,605 \\
Shimizu & 10,605 & Toyama & 10,605 \\
Akita & 10,605 & Tokuyama & 10,605 \\
Shibushi & 10,605 & Kanazawa & 10,605 \\
Sendai & 10,605 & Imari & 14,580 \\
Shimonoseki & 14,580 & *Busan & 114.6 \\
Kitakyushu & 14,580 & Port of East Japan & 28,300 \\
\hline
\end{tabular}

\footnotetext{
* The unit of handling cost in Busan is USD
} 
Stochastic Parameters. Except the waiting time, all the parameters in this simulation are stochastic. For most of the regional cities, we can obtain the maximum, mean and minimum values of transportation time. Since triangular distribution is recommended to be used in Monte Carlo simulation modeling when the underlying distribution is unknown, but a minimal value, some maximal value and a most likely value are available [14], we assume all the transportation time follow triangular distribution.

However, some transportation time just have mean value (only one service route), we need to estimate maximum, mean and minimum values of these parameters. Therefore, we calculated the minimum and maximum values by adding a multiplier $\alpha \%$. The value of $\alpha$ is estimated according to the correlation of existing maximum, mean and minimum values. Here $\alpha$ equals to 20 .

During the data collection, we got only mean values of transportation cost, so triangular distribution is not suitable for the simulation. As the fluctuation rate of cost is equally likely to be observed, we obtained uniform distribution to the transportation cost. All the values of cost can be multiplied by fluctuation rate $\beta \%$. The value of $\beta$ is observed by logistics expert [15]. In this paper, $\beta$ equals to 10 .

\subsection{The ARENA Simulation}

We firstly conducted Monte Carlo simulation by using an Excel spreadsheet to study this problem. We randomly generate every parameter to examine the total cost and time of one replication and aggregate the simulation result after 100 replications. However, Monte Carlo simulation is not very well suited for the simulation of dynamic models even though it is quite popular for static models [16]. For this reason, we developed an ARENA version 10.0 simulation model. The aim of this ARENA simulation study is to measure the waiting time at the port and visualize the dynamics of the process [17]. Meanwhile, the result of ARENA simulation can be compared with that of Monte Carlo simulation for examining the validity.

\section{Comparison of Simulation Results}

\subsection{Candidate Ports}

Twenty regional cities and twenty regional ports of Japan have been selected for this case study. For the mode via Japan, we chose the transit major port that is the closest to the regional city (Table 5).

Table 5. Corresponding Japanese major ports

\begin{tabular}{ccc|ccc}
\hline Regional City & Regional Port & $\begin{array}{c}\text { Closest Major Port } \\
\text { in Japan }\end{array}$ & Regional City & Regional Port & $\begin{array}{c}\text { Closest Major } \\
\text { Port in Japan }\end{array}$ \\
\hline Sapporo & Tomakomai & Tokyo & Hiroshima & Hiroshima & Kobe \\
Aomori & Hachinohe & Tokyo & Yamaguchi_1 & Tokuyama & Kobe \\
Akita & Akita & Tokyo & Yamaguchi_2 & Shimonoseki & Kobe \\
Sendai & Sendai & Tokyo & Matsuyama & Matsuyama & Kobe \\
Niigata & Niigata & Tokyo & Kitakyushu & Kitakyushu & Kobe \\
Toyama & Toyama & Nagoya & Hukuoka & Hakata & Kobe \\
Kanazawa & Kanazawa & Nagoya & Saga & Imari & Kobe \\
Shizuoka & Shimizu & Yokohama & Oita & Oita & Kobe
\end{tabular}




\begin{tabular}{ccc|ccc} 
Tsu & Yokkaichi & Nagoya & Kagoshima & Shibushi & Kobe \\
Okayama & Mizushima & Kobe & Naha & Naha & Kobe \\
\hline
\end{tabular}

\subsection{The Case of the North America Route}

The results show that most of the twenty regional cities - with the exception of Tsu, Okayama, Hiroshima, and Shizuoka (For Shizuoka, both Busan and Japan major port is acceptable) - enjoy cost advantages when using Busan for transshipment (See Table 6). On the other hand, Busan is also superior in terms of shipping time when a container is transported from Yamaguchi_2, Kitakyushu or Hukuoka city to Long Beach. The reason why the costs of transiting via Japan are largely higher is that the maritime transportation cost and handling cost are greater. Besides, the inland transportation cost in Japan is much higher than the maritime transportation cost between the regional Japanese port and Busan.

Table 7 provides the recommended target transshipment ports for regional Japanese cities. The regional cities Yamaguchi, Kitakyushu, and Hukuoka are located close to Busan; they enjoy advantages in both time and cost when Busan is used as the transshipment port. Thus, Busan can be a good option for the transshipment port for them. The results of Case I prove that Busan has strong competitive strength for transshipment

Table 6. Results of the comparison (Long Beach)

\begin{tabular}{|c|c|c|c|c|c|}
\hline \multirow{3}{*}{ Regional City } & \multicolumn{5}{|c|}{ Results of the Comparison (Long Beach) } \\
\hline & \multirow{2}{*}{ Regional Port } & \multicolumn{2}{|c|}{$\operatorname{Cost}($ USD) } & \multicolumn{2}{|c|}{ Time(days) } \\
\hline & & Busan & Japan & Busan & Japan \\
\hline Sapporo & Tomakomai & 2427.7 & 3625.5 & 18.2 & 12.0 \\
\hline Aomori & Hachinohe & 2407.3 & 2999.6 & 16.9 & 11.5 \\
\hline Akita & Akita & 2148.0 & 2888.3 & 15.7 & 11.7 \\
\hline Sendai & Sendai & 2142.8 & 2445.7 & 16.6 & 11.4 \\
\hline Niigata & Niigata & 2145.5 & 2418.4 & 16.5 & 11.4 \\
\hline Toyama & Toyama & 2013.1 & 2282.7 & 15.0 & 14.0 \\
\hline Kanazawa & Kanazawa & 2010.7 & 2132.7 & 16.1 & 13.8 \\
\hline Shizuoka & Shimizu & 2046.5 & 2041.6 & 16.5 & 13.2 \\
\hline Tsu & Yokkaichi & 2136.1 & 1708.9 & 18.2 & 13.6 \\
\hline Okayama & Mizushima & 2228.7 & 1928.9 & 15.2 & 14.4 \\
\hline Hiroshima & Hiroshima & 2180.9 & 2104.0 & 15.3 & 14.7 \\
\hline Yamaguchi_1 & Tokuyama & 2126.9 & 2521.0 & 15.3 & 14.8 \\
\hline Yamaguchi_2 & Shimonoseki & 2299.2 & 2528.5 & 13.8 & 14.6 \\
\hline Matsuyama & Matsuyama & 1967.3 & 2190.2 & 16.1 & 14.5 \\
\hline Kitakyushu & Kitakyushu & 2001.5 & 2664.9 & 13.1 & 14.8 \\
\hline Hukuoka & Hakata & 2014.6 & 2690.3 & 13.4 & 14.9 \\
\hline Saga & Imari & 2272.0 & 2817.7 & 16.8 & 15.0 \\
\hline Oita & Oita & 2154.8 & 2778.9 & 16.2 & 15.3 \\
\hline Kagoshima & Shibushi & 2004.8 & 3170.1 & 16.3 & 15.3 \\
\hline Naha & Naha & 2022.9 & 3497.5 & 18.2 & 15.8 \\
\hline
\end{tabular}


Table 7. Target transit port (Long Beach)

\begin{tabular}{|c|c|c|}
\hline \multicolumn{3}{|c|}{ Transit Port (Long Beach) } \\
\hline \multirow{2}{*}{ Regional City } & Cost & Time \\
\hline & \multicolumn{2}{|c|}{ Transit Port } \\
\hline Sapporo & Busan & Tokyo \\
\hline Aomori & Busan & Tokyo \\
\hline Akita & Busan & Tokyo \\
\hline Sendai & Busan & Tokyo \\
\hline Niigata & Busan & Tokyo \\
\hline Toyama & Busan & Nagoya \\
\hline Kanazawa & Busan & Nagoya \\
\hline Shizuoka & Yokohama/Busan & Yokohama \\
\hline Tsu & Nagoya & Nagoya \\
\hline Okayama & Kobe & Kobe \\
\hline Hiroshima & Kobe & Kobe \\
\hline Yamaguchi_1 & Busan & Kobe \\
\hline Yamaguchi_2 & Busan & Busan \\
\hline Matsuyama & Busan & Kobe \\
\hline Kitakyushu & Busan & Busan \\
\hline Hukuoka & Busan & Busan \\
\hline Saga & Busan & Kobe \\
\hline Oita & Busan & Kobe \\
\hline Kagoshima & Busan & Kobe \\
\hline Naha & Busan & Kobe \\
\hline
\end{tabular}

\section{Conclusion}

This paper has proposed simulation models of the container transportation network in the Busan-West Japan region in order to compare the transportation time and cost via two different transit ports and establish that Busan is more economical than other options as a transit port. An ARENA simulation model was firstly presented. Then, we conducted simulation experiments by using actual shipping data. Finally, we recommended the target cities/ports in West Japan after an analysis of the experiment results. From the analysis of the results of this paper, we can conclude that Busan is a highly competitive transit port for container transportation for the cities that are located on the western coast of Japan. However, currently there are a few shipping routes between these two regions. To obtain benefits for Busan and regional cities in West Japan, more cooperation should be established between both sides.

\section{References}

1. Wikipedia, http://www.wikipedia.org/, last accessed 2010 .

2. Busan Port Authority, http://www.busanpa.com/, last accessed 2010. 
3. Kim, H.T.: Construction of cooperative relationship between the port of Busan and Donghae coast ports of Japan. In: 2008 International Symposium on Maritime and Port Logistics, pp. 21-3528. Busan, Korea (2008).

4. Cortes, P., Munuzuri, J., Ibanez, J. N. and Guadix, J.: Simulation of freight traffic in the Seville inland port. Simulation Modeling Practice and Theory 15, 256-271 (2007).

5. Kim, K.H. and Kim, H.B.: Segregating space allocation models for container inventories in port container terminals. International Journal of Production Economics 59(1-3), 415-423 (1999).

6. Bruzzone, A. and Signorile, R.: Simulation and genetic algorithms for ship planning and ship yard layout. Simulation 71(2), 74-83 (1998).

7. Kose, E., Basar, E., Demirci, E., Gunerglu, A. and Erkebay, S.: Simulation of marine traffic in Istanbul Strait. Simulation Modeling Practice and Theory 11, 597-608 (2003).

8. Hayuth, Y., Pollatschek, M.A. and Roll, Y.: Building a port simulator. Simulation 63(3), 179-189 (1994).

9. Kang, I.D., Logitech, Hi, Personal Communication, Sept. (2009).

10. Williams, E. J. and Khoubyari, S.: Modeling issues in a shipping system. In: Proc. 1996 Winter Simulation Conference, pp. 1353-1358, (1996).

11. Main Cost of Transportation $\&$ Warehouse, $30^{\text {th }}$ ed., Sanbi printing Co., Ltd., Japan (2008).

12. Transportation Cost of Suit Product. Transportation Books Publication, Japan (1999).

13. Kenji, N. and Akira, N.: International Transportation Handbook. 2009 version. Ocean Commerce Ltd., Japan (2009).

14. Kotz, S., Dorp, J.R.V., Beyond beta: other continuous families of distributions with bounded support and applications. World Scientific Publishing Co. Pte. Ltd., Singapore (2004).

15. Kang, I.D., Logitech, Hi. Personal Communication, Sept. (2009).

16. Kelton, W. D., Sadowski, R. P. and Sturrock, D. T.: Simulation with ARENA, $4^{\text {th }}$ ed., McGRAW Hill, USA (2007).

17. Bapat, V. and Swets, N.: The ARENA product family: enterprise modeling solutions. In: Proc. 2000 Winter Simulation Conference, pp. 163-169, (2000). 